Revista Brasileira

de Estudos de

Cinema

e Audiovisual

\title{
Os jovens querem escutar música de qualquer jeito
} Adriano Chagas $^{1}$

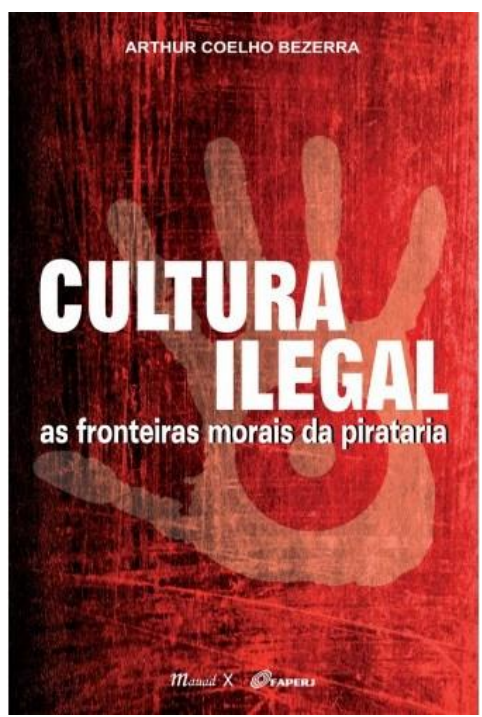

\section{Resenha}

BEZERRA, Arthur Coelho. Cultura ilegal: as fronteiras morais da pirataria. Rio de Janeiro: Mauad X: Faperj, 2014. 240p.

' Mestrando do Programa de Pós-graduação em Comunicação da Universidade Federal Fluminense. Especialista em Marketing e TV Digital. Graduado em Jornalismo. Professor da Universidade Estácio de Sá. Integrante do Entelas, grupo de pesquisa de televisão, imagem, teoria e recepção. e-mail: adriano.chagas@gmail.com 
O livro "Cultura llegal: as fronteiras morais da pirataria" apresenta uma sólida investigação sobre a prática de compartilhamento de bens culturais pela reprodução e download de CDs e DVDs. Esses comportamentos caracterizam um caminho para a solução de problemas de acesso à cultura e são tratados pelas grandes empresas como pirataria, ou seja, o roubo ilegal de bens culturais protegidos pelo direito de propriedade.

A origem da obra está na tese de doutoramento de Arthur Coelho Bezerra, defendida no Programa de Pós-graduação em Sociologia e Antropologia da Universidade Federal do Rio de Janeiro (PPGSA/UFRJ). O autor é professor do Programa de Pós-graduação em Ciência da Informação (PPGCI/IBICT-UFRJ) e elaborou o estudo a partir de entrevistas com um grupo de 48 jovens, iniciado em 2008, em Juiz de Fora (MG) e da etnografia de cerca de 20 camelôs, entre 2009 e 2010, no centro do Rio de Janeiro.

A primeira parte do livro foi chamada de "Cultura" e possui três capítulos. O inicial apresenta a vida social da cultura na modernidade, a partir de crenças, valores e visões de mundo. Promove um rastreamento histórico do bem cultural, através de seu trânsito nos lugares sociais. O percurso é iniciado nas invenções de máquinas e técnicas que transformaram, em definitivo, o modo de produção nas sociedades modernas.

Quando o autor observa a cultura como mercadoria, mostra que a digitalização, em diversos suportes, trouxe ganhos em espaço, tempo, fidelidade e facilitou o trânsito de conteúdos. Os computadores ampliaram a sua capacidade de processamento e armazenamento e o preço dos equipamentos eletrônicos de reprodução também caiu vertiginosamente. $E$ ainda houve outro fator decisivo: a chegada da internet. A cibercultura conferiu protagonismo aos usuários em relação aos bens copiados e distribuídos. O compartilhamento via redes $\mathrm{P} 2 \mathrm{P}$, download e upload, abre uma nova perspectiva de relacionamento com a música, em um primeiro momento e, mais tarde, com qualquer outro conteúdo, em várias plataformas. Os jovens se tornam os mais vorazes consumidores de bens, graças à habilidade com a informática e à presença das redes sociais e das ferramentas de interação, em sua própria casa, no lar de amigos ou em lan houses. 
O segundo capítulo aborda o download e a compra de conteúdo pirata, a partir dos depoimentos pesquisados, que levaram à construção de um perfil típico do jovem com acesso às tecnologias digitais, ao conteúdo cultural e às redes sociais. Os números da pesquisa são a base para a apresentação de como o surgimento da internet revolucionou o acesso à informação e ao entretenimento, e fez surgir novos comportamentos, entre eles a prática do download e do streaming como formas de consumo de informação, entretenimento e cultura.

Os entrevistados que se assumem consumidores de produtos piratas alegam motivos como a facilidade do acesso e o baixo preço. Os demais defendem a preferência por produtos originais. Para encaminhar a análise, o autor disseca as características estruturais do mercado cultural formal, especialmente as indústrias fonográficas e cinematográficas, enquanto intercala trechos dos depoimentos dos jovens sobre os aspectos que envolvem as políticas de fixação de preços dos bens pela indústria. Os respondentes caracterizam as suas práticas como amorais, estão cientes da transgressão e têm técnicas para neutralizar sua culpabilidade. Apresentam os valores sociais como guias qualificados para a ação, configurando uma área nebulosa, compreendida entre a justificativa de um ato ilícito e a explicação de uma conduta legítima, a respeito de práticas que envolvem produtos culturais caros e dispensáveis.

O terceiro capítulo apresenta três dilemas do acesso à cultura. O primeiro é o da descentralização do acesso; o outro é o da produção cultural amadora; e o terceiro é o da propriedade dos bens culturais, onde reside o conflito entre o direito da coletividade de acesso aos bens e os mecanismos e acordos internacionais que garantem ao criador a propriedade intelectual e os frutos morais e materiais de sua obra.

O capítulo aborda ainda a evolução histórica da regulação da propriedade intelectual e dos direitos autorais. O uso do bem cultural, assim, se apresenta desdobrado em dois aspectos. Um é intangível, se refere à personalidade do autor, aos direitos morais. $\mathrm{O}$ outro se refere aos direitos patrimoniais, à exploração comercial das obras. A pesquisa aborda ainda a evolução histórica, no Brasil, dos dois sistemas dominantes sobre os direitos autorais: o copyright e o direito de 
autor. Comprar ou vender cópias de músicas, filmes, jogos e programas de computador, baixar filmes, copiar livros inteiros, CDs ou DVDs, configura uma forma de acesso proibida por lei.

A segunda parte do livro, o quarto capítulo, batizado de "llegal", apresenta como os agentes audiovisuais e as indústrias de conteúdo atuam para coibir as práticas que representam uma expressiva parte do trânsito de bens: o comércio de mídias nas ruas e a cópia de arquivos na internet. Vários organismos compõem o grupo dos empreendedores morais da cultura, que buscam o respaldo da opinião pública para sua cruzada de combate às práticas ilegais. Eles são contrários às cópias não autorizadas, argumentam que se trata de um malefício para a sociedade e defendem que, na ausência de uma proteção forte à propriedade intelectual, não haveria mais conteúdo à disposição dos consumidores.

A pesquisa aponta as ações que definiram a pirataria como alvo e inimigo número um, diante da opinião pública. E mostra que as cruzadas morais destes grupos comtemplam programas educativos de combate à pirataria, patrocinados pelo setor privado com aprovação do setor público, além de campanhas publicitárias. Seu conteúdo vai da instrução aos consumidores à responsabilização dos espectadores pelos danos, com slogans ameaçadores. A pirataria acaba associada ao download de arquivos, ao crime de furto e ao crime organizado.

Paralelamente, a cruzada jurídica para inibir as práticas ilegais inclui pressões econômicas, proteções tecnológicas e lobby político. No Brasil, explica o autor, o código penal cria uma exceção para a cópia privada sem intuito de lucro, tornando esta prática um ilícito civil, em vez de criminal. Como é difícil separar o trânsito legal de bens culturais do ilegal, a estratégia dos detentores de direitos é simples: barrar qualquer trânsito. Para o setor público, a questão é o preço e o acesso aos bens. A troca de arquivos na internet, assim, é repetida por milhões de usuários e configura um problema para os empreendedores morais da cultura: não mais combater a atividade em si, mas a conquista da legitimidade de suas ações junto à sociedade. 
As representações dos 48 jovens ouvidos na pesquisa sobre o trânsito de bens culturais por meio de práticas ilegais que caracterizam a pirataria estão em evidência no capítulo cinco, incluindo suas contradições a respeito das práticas de download e o caráter ilegal da atividade. Como a maioria não possui intenção de lucro financeiro, eles não se enxergam como infratores da lei, tampouco se reconhecem como protagonistas de uma prática criminosa.

Neste momento do livro, os jovens também apontaram aqueles que ganham e os que perdem com a pirataria, questão que contribuiu para o autor aprofundar o conhecimento do fenômeno com o grupo de entrevistados, a partir da identificação de três aspectos: a primeira é a distância entre o grupo dos prejudicados, integrado por profissionais e instituições formais, do grupo dos beneficiados, onde figuram trabalhadores informais e ilegais; a segunda é a presença de categorias opostas dentro do próprio grupo: todos ganham $\mathrm{x}$ ninguém ganha; e, por último, vários grupos são indicados nas duas listas, como artistas, vendedores de discos piratas, consumidores, sociedade e população.

Os argumentos contrários à cópia de bens culturais são solidários ao trabalho de artistas e produtores. Nenhum dos entrevistados se declarou exclusivamente a favor da pirataria. Quando endossam a prática, eles se referem ao download pela internet. A condenação moral, assim, estaria na comercialização da obra de outra pessoa, na busca pelo lucro por meio da cópia pirata de um produto oficial. Neste momento da leitura do livro surgiu a ideia do título desta resenha, adaptado do depoimento de um dos 48 jovens entrevistados pelo autor.

No sexto e último capítulo, a obra apresenta os frutos de uma observação etnográfica da atuação de comerciantes de mídias piratas no centro do Rio de Janeiro e da realização de entrevistas semidirigidas por meio de abordagens informais. Foram ouvidos cerca de vinte vendedores, em níveis de aproximação distintos, sem a identificação do autor como pesquisador (na maioria dos casos), com a gravação do áudio das conversas pelo telefone celular.

Alguns entrevistados detalharam suas motivações e o esquema de remuneração da atividade. A localização do trabalho se mostrou estratégica, embora haja aqueles que atuem nos sinais, ônibus, bares ou praias: os 
ambulantes. Os fixos, que trabalham em barracas em camelódromos, são legalizados ou não. E os nômades operam em pontos onde há grande fluxo de pedestres. São preocupações dos comerciantes de mídias piratas a repressão, por meio da atuação da Guarda Municipal e as fiscalizações e ações das polícias Militar e Civil. Mas a atuação no comércio de mídias piratas é legitimada pelos próprios vendedores, o que conduziu o autor a observar, mais uma vez, as fronteiras embaçadas entre o legal e o ilegal.

O capítulo ainda mostra que os grupos industriais tentam associar a pirataria em média e longa escala a um esquema de crime organizado, em um embaralhamento da fronteira entre pirataria, falsificação e contrabando. Este último, por exemplo, está presente no comércio ilegal de bens culturais que depende de matéria-prima específica, ou seja, mídias virgens chinesas. Mas, em longo prazo, há a tendência da substituição gradual da atividade pela praticidade do ambiente online, como já ocorre em países desenvolvidos.

Em sua conclusão, o livro evidencia que a descoberta de técnicas de reprodução de bens não é suficiente para explicar o surgimento deste mercado. $O$ verbo ganhar assume uma dupla percepção: a população, com baixos salários, ganha com a pirataria por causa da ampliação do acesso à cultura. $\mathrm{Na}$ configuração de comercialização, o aspecto comunitário é deixado de lado para a exaltação do ganho escuso, que gera malefícios para toda a cadeia produtiva. As fronteiras morais migram de lugar. A pirataria expande o consumo popular, mas também gera condições de trabalho, quase um espírito empreendedor. Dessa forma, o livro mostra como os comerciantes e os consumidores são evocados a negociar a aceitação de suas atividades, condicionados às variações nas fronteiras morais, redefinidas de acordo com o contexto.

$\mathrm{Na}$ diferença entre o ilegal e o lícito, os fluxos de mercadorias, informações e pessoas são ilegais porque desafiam as normas das autoridades formais, mas poderiam ser vistos como lícitos pelas pessoas envolvidas nas transações. No caso do download, as transformações no campo moral têm se aproximado da velocidade das inovações tecnológicas, mas a normativa jurídica está obsoleta. As transformações sociais, encerra o autor, continuarão rendendo frutos para a 
ampliação das investigações, a partir da aparição de outros olhares sobre os fenômenos em evidência na pesquisa. $E$ apenas a adequação de novos marcos regulatórios poderá reaproximar agentes, produtores e distribuidores de conteúdo, dentro dos hábitos de consumo cultural emergentes nas redes, nesta era marcada pela variedade das técnicas de reprodução digital de conteúdo.

Assim, trata-se de uma obra atual e necessária para os campos de estudos do consumo e do audiovisual, apresentando uma sólida contextualização teórica para o uso em citações e referências. O autor aborda o tema de forma sensível e integral, considerando a constante evolução dos meios e a volatilidade que rege o objeto de análise. 